\title{
Orman Karıncalarının (Formica rufa grup) Mikroeklembacaklı Komünite Yapısına Etkisi
}

\author{
Meriç ÇAKIR \\ Çankırı Karatekin Üniversitesi, Orman Fakültesi, Toprak İlmi ve Ekoloji Anabilim Dalı, 18200, Çankırı
}

\section{Öz}

Kuzey yarım kürede yaygın olarak bulunan orman karıncaları (Formica rufa grubu) ibre, dal, ağaç kabuğu, reçine ve otsu türler kullanarak toprak üzerinde tepecik halinde yuva yaparlar. Yuva yapımında kullanılan organik madde, yuva etrafındaki toprakların özelliklerini değiştirir. Ayrıca orman karıncaları yiyecek arama faaliyetleriyle de yuva etrafındaki toprakların özelliklerini ve diğer canlıları etkilerler. Orman karıncalarının, mikroeklembacaklılar üzerindeki etkisini belirlemek için yürütülen bu çalışma, Çankırı Karatekin Üniversitesi Araştırma Ormanında gerçekleştirilmiştir. Karaçam (Pinus nigra) ormanında seçilen dört adet benzer hacimdeki $\left(0,54 \pm 0,05 \mathrm{~m}^{3}\right)$ kırmızı orman karıncası yuvasının yanından $(0,5 \mathrm{~m})$ ve $10 \mathrm{~m}$ uzağından çelik silindirler ile mikroeklembacaklılar örneklenmiştir. Teşhisleri ve sayımları yapılan mikroeklembacaklıların komünite yapıları ve çeşitlilik indeks değerlerine tekrarlı ölçümlerde varyans analizi ile uygulanarak değerlendirilmiştir. Sonuç olarak mikroeklembacaklıların miktarı ile farklı beslenme seviyelerindeki (çürükçül, yırtıcı ve otçul) canlıların miktarları yuvadan uzaklaştıkça artmıştır. Bununla birlikte karınca yuvalarının mikroeklembacaklı çeşitliliğini düşürdüğü belirlenmiştir.

Anahtar Kelimeler: Formica rufa, collembola, akar, yırtıcı, çürükçül.

\section{Effect of Wood Ants (Formica rufa group) on Community Structure of Microarthropod}

\begin{abstract}
Wood ants (Formica rufa group) are mostly found across the northern hemisphere, they generally use needle, branch, bark, resin, and herbaceous species to construct the nest as a mound on the soil. The organic matter which is used in nest construction changes the properties of the soils adjacent to the nest. They also affect soil properties and other fauna around the nest through foraging activities. This study, conducted to determine the effects of wood ants on microarthropods, was carried out in Çankırı Karatekin University Research Forest, Çankırı-Turkey. Microarthropods were sampled with steel core from the adjacent $(0.5 \mathrm{~m})$ and $10 \mathrm{~m}$ away from the four similar volumes $\left(0.54 \pm 0.05 \mathrm{~m}^{3}\right)$ of the wood ant nests selected in the black pine (Pinus nigra) forest. The community structures and diversity index values of the microarthropods, which were identified and counted, were evaluated by repeated measurements with ANOVA. As a result, the density of microarthropods and the number of organisms at different trophic levels (detritivore, predator, and herbivorous) increased $10 \mathrm{~m}$ away from the nest. Additionally, it has been determined that wood ant nests decrease of the diversity of microarthropods.
\end{abstract}

Keywords: Formica rufa, collembola, acari, predator, detritivore. 


\section{Giriş}

Ekosistem mühendisi olarak adlandırılan karıncalar (Jones ve ark., 1994; Lavelle ve ark., 1997) toprağın biyolojik olarak karıştırılması, havalanması organik maddenin ayrışması ve besin maddelerinin mineralizasyonu süreçlerinde önemli katkıları bulunmaktadır (Jouquet ve ark., 2006; Domisch ve ark., 2008).

Orman ekosistemlerinde önemli karınca türlerinden biri olan Orman karıncaları (Formica rufa grubu) kuzey yarımkürede yaygın olarak bulunurlar (Stockan ve Robinson, 2016). Toprak üzerinde tepecik halinde yuva yapan orman karıncalarının, toprak üstü ve toprak altı yuva hacimleri birbirine yakındır (Jurgensen ve ark., 2008). Yuvanın toprak üstü kısmı ibre, dal, ağaç kabuğu, reçine ve otsu türler kullanılarak yapılmaktadır (Jílková ve ark., 2011). Biriktirilen bu organik madde yuvanın pH'sını doğrudan ve dolaylı olarak etkilemektedir (Jílková ve ark., 2012). Orman karıncaları yuvalarında koridorlar ve odalar inşa ederler ve bu yapılar yuvaların yakınındaki toprakların gözenekliliğini ve havalanmasını etkiler (Frouz ve Jilkova, 2008). Sonuç olarak, orman karıncaları yuvalarını inşa ederken, yuva etrafındaki toprakların özelliklerini değiştirerek yuvalarında belirli koşullar yaratırlar.

Orman karıncaları yiyecek arama faaliyetleriyle (foraging) yuva dışındaki toprak özelliklerini değiştirebilirler (Frouz ve Jilkova, 2008). Esas olarak ağaç üzerinde ve ölüörtü tabakasında yiyecek aradıklarından, toprak faunası üzerindeki etkilerinin düşük olduğu kabul edilmektedir (Skinner, 1980). Orman karıncaları toprak üstünde ve ağaç tepe çatısında bol miktarda bulunan omurgasızları avlandığından toprak mikroeklembacaklılar üzerindeki etkileri birçok çalışmada önemsiz bulunmuştur (Laakso ve Setälä, 2000; Lenoir ve ark., 2003; Robinson ve ark., 2016). Fakat orman zemininde yiyecek aramaya zorlandıklarında, orman karıncalarının toprak faunası üzerinde bazı etkileri olduğu belirtilmiştir (Lenoir, 2003). Robinson ve ark. (2016) yiyecek arama faaliyetinin toprak faunasını doğrudan (rakip avcıları bastırarak) veya dolaylı olarak (otsu bitkilerin sayısını azaltıp ölüörtü kalitesinin bozulmasına neden olarak) etkileyebileceğini belirtmiştir. Yuvalarını inşa ederken topladıkları ibreler ile ölüörtü miktarını azaltan orman karıncaları besin döngüsünü de etkilerler. Böylece yiyecek arama faaliyetleri ve ayrışma üzerindeki etkileri ile mikroeklembacaklı komünite yapısını etkilerler (Stadler ve ark., 2006; Domisch ve ark., 2008). Ayrıca orman karıncaları Coleoptera, Araneae ve Chilopoda gibi diğer yırtıcılardan daha saldırgan olduklarından dolayı mikroeklembacaklıların miktarını etkileyebilmektedirler (Moore ve ark., 1988; Laakso ve ark., 1995).

Toprak, farklı beslenme seviyelerinde ve boyutlarda sayısız canlıya ev sahipliği yapmaktadır (Coleman ve ark., 2018). Mikroeklembacaklılar ölüörtü ve toprağın üst katmanlarında yaşayan, boyutları $100 \mu \mathrm{m}$ ile $2 \mathrm{~mm}$ arasında olan canlılardır (Swift ve ark., 1979). Mikroeklembacaklılar ayrışma, besin döngüsü ve birincil üretim gibi ekosistem süreçlerinde önemli rol oynarken aynı zamanda toprak biyoçeşitliliğinin de büyük kısmını oluştururlar (Cole ve ark., 2006; Wagg ve ark., 2014).

Orman karıncalarının toprak mikroeklembacaklıları üzerindeki etkisine ilişkin literatür sınırlıdır. Bu çalışmanın amacı Formica rufa yuvalarının toprak mikroeklembacaklılarının komünite yapılarına ve çeşitliliklerine olan etkilerinin belirlenmesidir.

\section{Materyal ve Metot}

\section{1. Çalışma Alanı ve deneme deseni}

Araştırma, Çankırı Karatekin Üniversitesi Araştırma Ormanında (40³0'33" K, 3326'20" D) gerçekleştirilmiştir. Araştırma Ormanı 367 ha alanı kapsamakta olup karaçam (Pinus nigra Arnold.), sarıçam (Pinus sylvestris L.) ve meşe (Quercus infectoria Oliv. ve Quercus robur L.) türlerini içermektedir. Yarıkurak iklim kuşağında yer alan araştırma alanının yıllık ortalama yağışı 486 mm, yıllık ortalama sıcaklığı ise 10,5 ${ }^{\circ} \mathrm{C}$ dir. Anakaya Miyosen-Pliyosen kaynaklı serpantin kayasıdır (Çakır, 2019).

Örneklenen orman karıncası yuvaları, ortalama 86 yaşındaki saf karaçam meşceresi içinden seçilmiştir. Ağaçların ortalama çap1 $19 \mathrm{~cm}$, ortalama boyu $13 \mathrm{~m}$ ve hektardaki ortalama ağaç sayısı 797 dir. Yükseltisi 1365 m, eğimi \%10-15 ve kuzey bakıda yer almaktadır. Ölüörtü $3 \mathrm{~cm}$ kalınlığında yaprak, çürüntü ve humus katmanlarını içeren Eumesoamphi humus tipindedir. Toprak özellikleri sı̆̆ $(36 \mathrm{~cm})$, hafif asidik (pH: 6,44), orta derecede kireçli $\left(\mathrm{CaCO}_{3}\right.$ : \%3,87) ve killi türdedir (Çakır ve ark., 2020). Araştırma ormanı yüzlerce orman karıncası (Formica rufa L.) yuvasını içermektedir. Örnek alandaki yuva yoğunluğu hektarda ortalama 5-10 adet ve yuva hacimleri 0,2 ile 1,5 m3 arasında değişmektedir (Çakır, 2019). 


\subsection{Mikroeklembacaklıların Örneklenmesi ve Tanımlanması}

Toprak mikroeklembacaklıların örneklemesi, Ekim 2014 ile Eylül 2016 tarihleri arasında 2 y1l boyunca, benzer hacimdeki $\left(0,54 \pm 0,05 \mathrm{~m}^{3}\right)$ dört kırmızı orman karıncası yuvasında gerçekleştirilmiştir. Belirlenen dört yuva, aralarında en az 50m mesafe olacak şekilde seçilmiştir. Yuvaların topraküstü çapı, yüksekliği ve tepe noktasının çapı ölçülerek, hacimleri AutoCAD yazılım paketi ile hesaplanmıştır.

Yiyecek arama (foraging) mesafesi (etki mesafesi), karıncaların yuvalarından farklı mesafelerdeki etkilerini değerlendirmesi için önemlidir. Karıncaların yiyecek arama faaliyetlerini ve popülasyon yoğunluklarını etkileyebilecek, yuva boyutundaki farklılıklardan kaynaklanan belirsizliği önlemek için, dört adet yaklaşık aynı hacimdeki (yaklaşık 0,50 m3) karınca yuvaları seçilmiş ve iki farklı mesafeden mikroeklembacaklı örneklemesi yapılmıştır. Belirlenen iki farklı örnekleme bölgesi F. rufa aktivitesine göre tanımlanmıştır: (1) Yuva yanı, yuva kenarından 0,5 m mesafede, nispeten yüksek düzeyde karınca aktivitesinin gözlemlendiği dairesel bir alandır. (2) Yuva uzağı, yuva kenarından $10 \mathrm{~m}$ uzaklıkta bulunan, karınca aktivitesinin gözlenmediği alandır. Bu bölgelerin seçimi Duma (2003) ve Reznikova ve Dorosheva (2004) çalışmaları da dikkate alınarak belirlenmiştir. Hem yuva yanı hem de yuvadan uzak bölgeden mikroeklembacaklı örnekleri alınmıştır. Üç adet çelik silindir $\left(100 \mathrm{~cm}^{3}\right)$ (ölüörtü ve mineral toprak dahil) ile örneklenen mikroeklembacaklılar 2 yıl boyunca her bölgeden iki ayda bir alınmıştır ( 4 yuva $\times 2$ mesafe $\times 3$ çelik silindir $\times 12$ ay = 288 örnek). Mikroeklembacaklılar, Berlese hunisi (Coleman ve ark., 2018) kullanılarak çıkartılmış ve daha sonra, stereoskopik binoküler mikroskop (Leica S8 APO; Leica Microsystems, Almanya) yardımı ile sınıflandırılmış, tanımlanmış ve yoğunlukları hesaplanmıştır. (Dindal, 1990).

\subsection{Toprak Örneklerinin Alınması ve Analizi}

Karınca yuvalarının yanından $(0,5 \mathrm{~m}$ mesafede) ve $10 \mathrm{~m}$ uzağından mikroeklembacaklılar örneklenirken toprak termometresi ile toprak sıcaklığı ölçülmüştür. Ayrıca mikroeklembacaklıların örneklendiği yerin hemen yanından bozulmuş toprak örneği ile ölüörtü örneği $(20 \mathrm{~cm} \times 20 \mathrm{~cm})$ alınarak laboratuvarda nem tayini ve pH analizi yapılmıştır. Nem tayini için toprak örnekleri $105^{\circ} \mathrm{C}$ de ölüörtü örnekleri ise $65{ }^{\circ} \mathrm{C}$ de sabit ağırlığa gelinceye kadar kurutulmuş ve yüzde nem miktarı hesaplanmıştır. pH analizi cam elektrotlu pH metre ile 1/2,5 oranındaki toprak saf su $\left(\mathrm{H}_{2} \mathrm{O}\right)$ süspansiyonunda ölçülmüştür (Karaöz, 1989).

\subsection{Indeksler}

Toprak mikroeklembacaklılarının biyolojik çeşitliliği, gözlemlenen takson sayısı, Shannon-Weiner $\left(H^{\prime}\right)$ ve Pielou's evenness $\left(J^{\prime}\right)$ çeşitlilik indeksleri kullanılarak değerlendirilmiştir (Gülsoy ve Özkan, 2008; Özkan, 2016). Çeşitlilik indeksleri, belirlenen taksonomik seviyede tanımlanan her numunede gözlemlenen örnek sayısı kullanılarak hesaplanmıştır. Toprak kalitesi Akar/Collembola oranı (A/C) ile tahmin edilmiştir (Menta ve ark., 2014).

\section{3. İstatistiksel Analizler}

Karınca yuvasının toprak özelliklerine, mikroeklembacaklıların komünite yapısına ve bazı çeşitlilik indekslerine olan etkisini belirlemek tekrarlı ölçümlerde varyans analizi uygulanmıştır (SPSS, 2011). Çeşitlilik indekslerinin belirlenmesinde biyolojik çeşitlilik bileşenleri (BİÇEB) hesaplama yazılımı kullanılmıştır (Özkan ve ark., 2020).

Kırmızı orman karıncasının, toprak mikroeklembacaklı miktarına olan etkisini gösterebilmek için bolluk analizi (RDA) Canoco versiyon 5.0 programı kullanılarak değerlendirilmiştir. Ordinasyon tekniği seçiminde en uzun gradyentin uzunluğu 4'ten az olduğu için lineer teknik olan RDA yöntemi kullanılmıştır (Šmilauer ve Lepš, 2014).

\section{Bulgular}

\subsection{Toprak Özellikleri}

Kırmızı orman karıncası yuvasına 0,5 m ve 10 m mesafeden alınan toprak sıcaklığı, nemi, pH verileri ve ölüörtünün nem ve pH değerlerine ait istatistiksel analiz sonuçları Tablo 1'de verilmiştir. İstatistik analiz sonuçlarında göre sıcaklık, nem ve pH değerleri yıl içerisindeki değişimi önemli iken $(P<0,01)$ karınca 
yuvasının bu faktörler üzerine etkisi istatistiksel olarak önemsizdir $(P>0,05)$ (Tablo 1).

Tablo 1. Orman karıncalarının yuva yanı ve yuva uzağına ait bazı toprak özellikleri.

\begin{tabular}{llllll}
\hline & $\begin{array}{l}\text { Yuva yanı } \\
(\mathbf{0 , 5} \text { m) }\end{array}$ & $\begin{array}{l}\text { Yuva uzağı } \\
(\mathbf{1 0 m})\end{array}$ & $\begin{array}{l}\text { P- değeri } \\
\text { Zaman }\end{array}$ & $\begin{array}{l}\text { P- değeri } \\
\text { Mesafe }\end{array}$ & $\begin{array}{l}\text { P- değeri } \\
\text { Zaman } \boldsymbol{x} \text { Mesafe }\end{array}$ \\
\hline Toprak sıcaklığı $\left({ }^{\circ} \mathbf{C}\right)$ & $10,69 \pm 0,67$ & $10,40 \pm 0,45$ & $\mathbf{0 , 0 0 0}$ & 0,192 & 0,297 \\
Toprak nemi (\%) & $24,61 \pm 5,16$ & $22,39 \pm 7,26$ & $\mathbf{0 , 0 0 0}$ & 0,284 & 0,694 \\
Ölüörtü nemi (\%) & $54,16 \pm 8,74$ & $55,78 \pm 8,92$ & $\mathbf{0 , 0 0 0}$ & 0,238 & 0,581 \\
pHToprak & $6,27 \pm 0,30$ & $6,22 \pm 0,25$ & $\mathbf{0 , 0 0 0}$ & 0,565 & 0,769 \\
pHölüörtü & $5,00 \pm 0,04$ & $5,07 \pm 0,05$ & $\mathbf{0 , 0 0 0}$ & 0,361 & 0,354 \\
\hline
\end{tabular}

Karınca yuvalarının $0,5 \mathrm{~m}$ ve $10 \mathrm{~m}$ mesafeden alınan toprak sıcaklığı değerleri, yuva içerisinden alınan sıcaklık değerlerine kıyasla düşük bulunmuştur $(P=0,021)$ (Şekil 1).

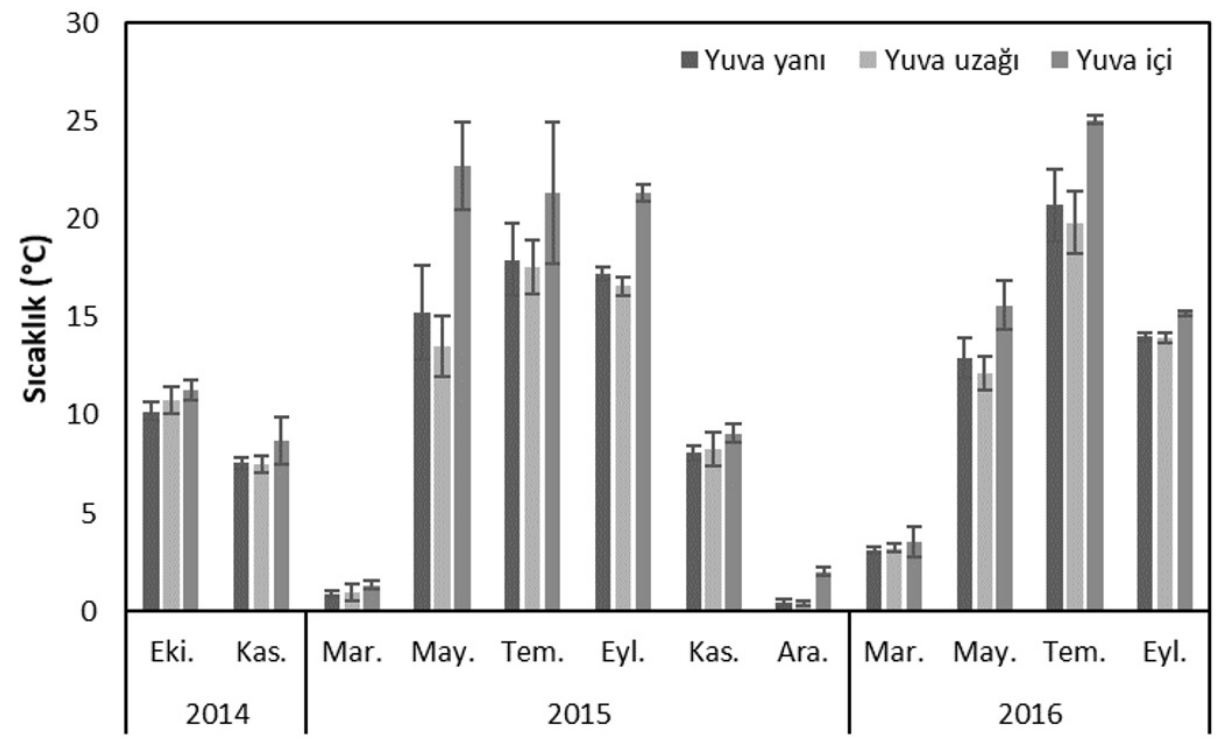

Şekil 1. Sıcaklığın yuva içerisinde, kenarında $(0,5 \mathrm{~m})$ ve uzağındaki $(10 \mathrm{~m})$ değişimi.

Toprak ve ölüörtü neminin yıl içerisindeki miktarı önemli düzeyde değişmektedir $(P<0,01)$ (Tablo 1$)$. Toprak ve ölüörtü neminin 2015 Mart ile 2015 Temmuz ayları arasındaki değerleri, 2016 Mart ile 2016 Temmuz ayları arasındaki değerleri ile kıyaslandığında daha düşük olduğu görülmektedir (Şekil 2). Fakat bu değişimler kırmızı orman karıncası yuvalarından bağımsızdır $(P>0,05)$ (Tablo 1$)$.
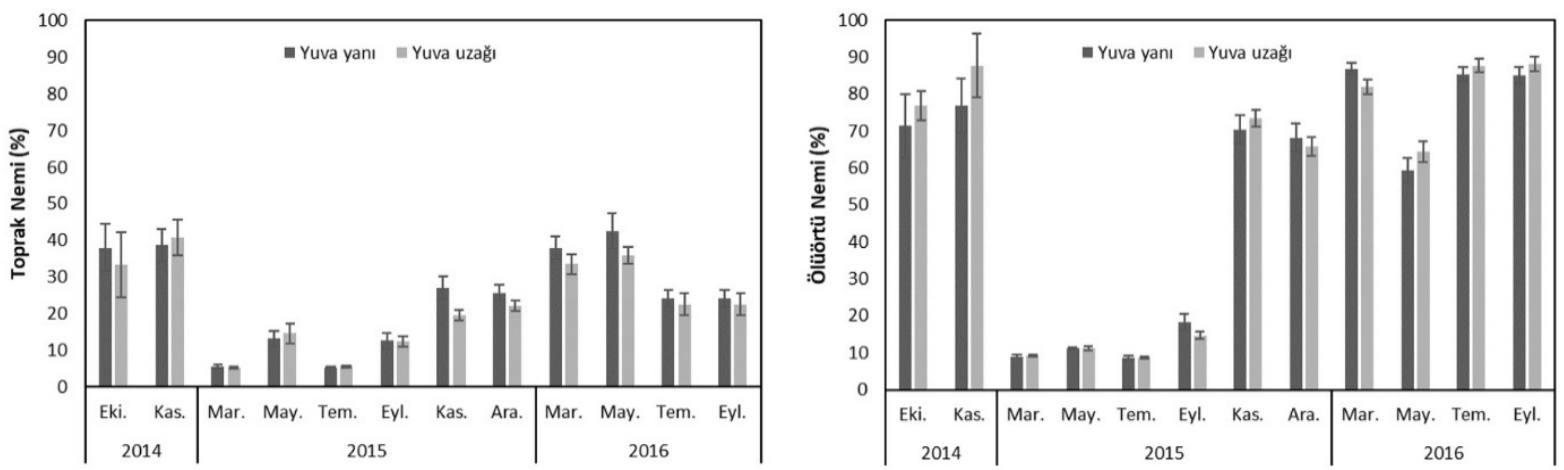

Şekil 2. Toprak ve ölüörtü neminin yuva kenarında (0,5 m) ve uzağındaki (10 m) değişimi.

Toprak pH’sının yıl içerisindeki dalgalanması göreceli olarak daha azdır (Şekil 3). Toprak ve ölüörtü pH's1 yıl içerisinde zamansal olarak değişirken $(P<0,01)$ bu değişimi karınca yuvası etkilememektedir $(P>0,05)$. Ayrıca 
2015 Eylül ayından sonra hem toprak hem de ölüörtü pH'sında bir artış olduğu görülmektedir (Tablo 1). Yıllar arasındaki bu artış istatistiksel olarak anlamlıdır $(P=0,000)$.
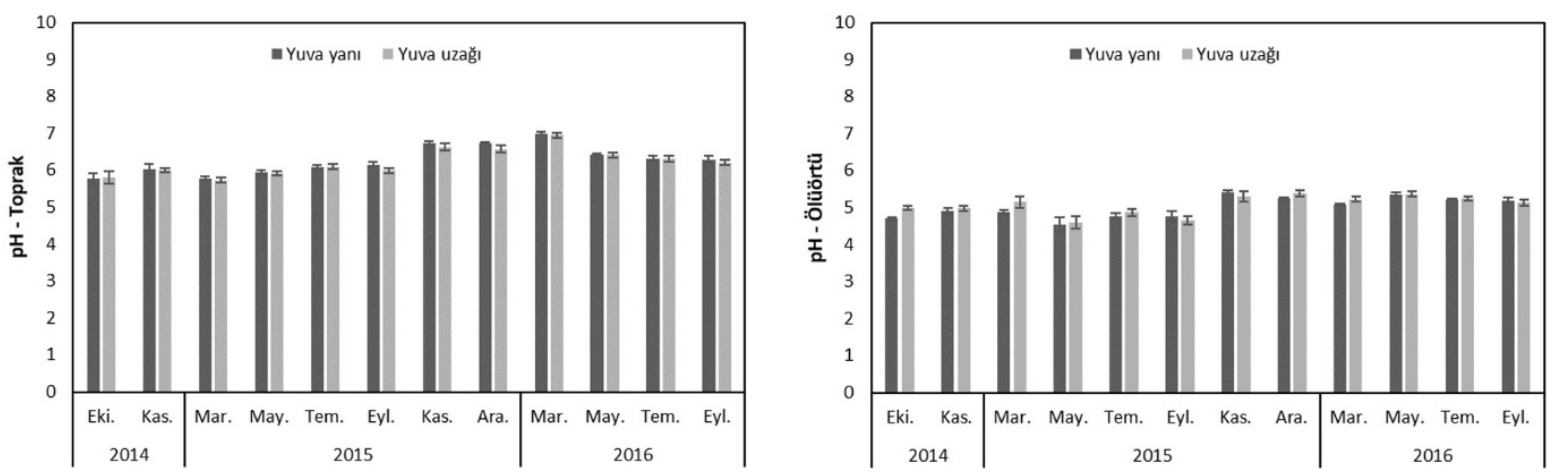

Şekil 3.Toprak ve ölüörtü pH’sının yuva kenarında (0,5 m) ve uzağındaki (10 m) değişimi.

\subsection{Mikroeklembacaklıların Komünite Yapısı}

Bolluk analizi ile elde edilen eksen $1(\% 16,47)$ ve eksen 2 (\%6,21), varyasyonun \%22,68'ini açıklamaktadır. Monte Carlo önem testi, RDA'nın tüm eksenlerinin önemli olduğunu $(P=0,001)$ ve karınca yuvasından uzaklaştıkça mikroeklembacaklı yoğunluğunun arttı̆̆ını göstermektedir. Şekil 4 orman karıncasının mikroeklembacaklılar üzerindeki etkisini açık bir şekilde göstermektedir.

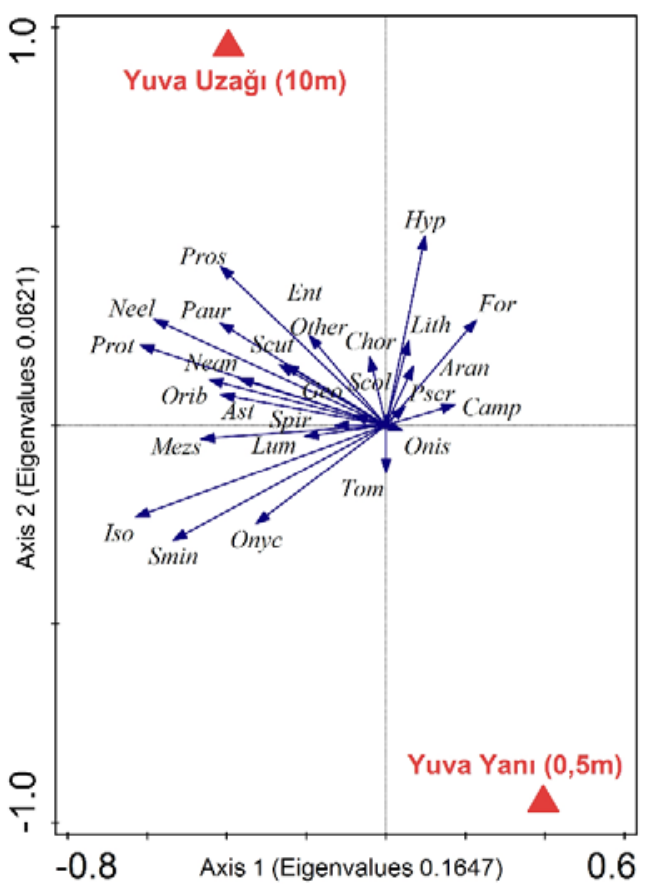

Şekil 4. Orman karıncası yuvasının yanı $(0,5 \mathrm{~m})$ ve uzağında $(10 \mathrm{~m})$ belirlenen mikroeklembacaklıların dağılımını gösteren bolluk analizi (RDA) diyagramı. Orib: Oribatida, Mezs: Mesostigmata, Pros: Prostigmata, Ast: Astigmata, Ent: Entomobryidae, Tom: Tomoceridae, Iso: Isotomidae, Smin: Sminthuridae, Neel: Neelidae, Nean: Neanuridae, Onyc: Onychiuridae, Hyp: Hypogastruridae, Spir: Spirobolidae, Chor: Chordeumatida, Lith: Lithobiomorpha, Geo: Geophilomorpha, Onis: Oniscidae, Prot: Protura, Paur: Pauropoda, Aran: Araneae, Camp: Campodeidae, Pscr: Pseudoscorpionida, Scol: Scolopendrellidae, Scut: Scutigerella, For: Formicidae, Lum: Lumbricina, Other: Diğer.

Toplam mikroeklembacaklı miktarı ile Collembola ve Akar taksonlarının miktarları yıl içerisinde değişiklik göstermektedir $(P<0,01)$. Ayrıca orman karıncası yuvasından uzaklaştıkça da miktarları artmaktadır $(P<0,01)$ (Tablo 2). Orman karıncası yuvasından 10m uzakta toplam mikroeklembacaklı (\%34), Collembola (\%37) ve Akar (\%32) miktarları, yuvanın yanına kıyasla daha yüksek bulunmuştur. A/C indeksi değerine göre örnekleme bölgeleri arasında istatistiksel bir fark bulunamamıştır (Tablo 2). Mikroeklembacaklıların komünite yapısı, beslenme alışkanlıklarına göre sınıflandırıldığında çürükçül, yırtıcı, otçul ve hepçillerin miktarlarının yıl içerisindeki değişimi (Şekil 5) istatistiksel olarak farklılık göstermektedir $(P<0,01)$ (Tablo 2). 
Bununla birlikte yuvadan uzaklaştıkça çürükçül, yırtıcı ve otçul beslenme yapısındaki mikroeklembacaklıların miktarı sırası ile \%29, \%43 ve \%163 artmış ve bu değişim istatistiksel olarak anlamlıdır $(P<0,01)$ (Tablo 2).
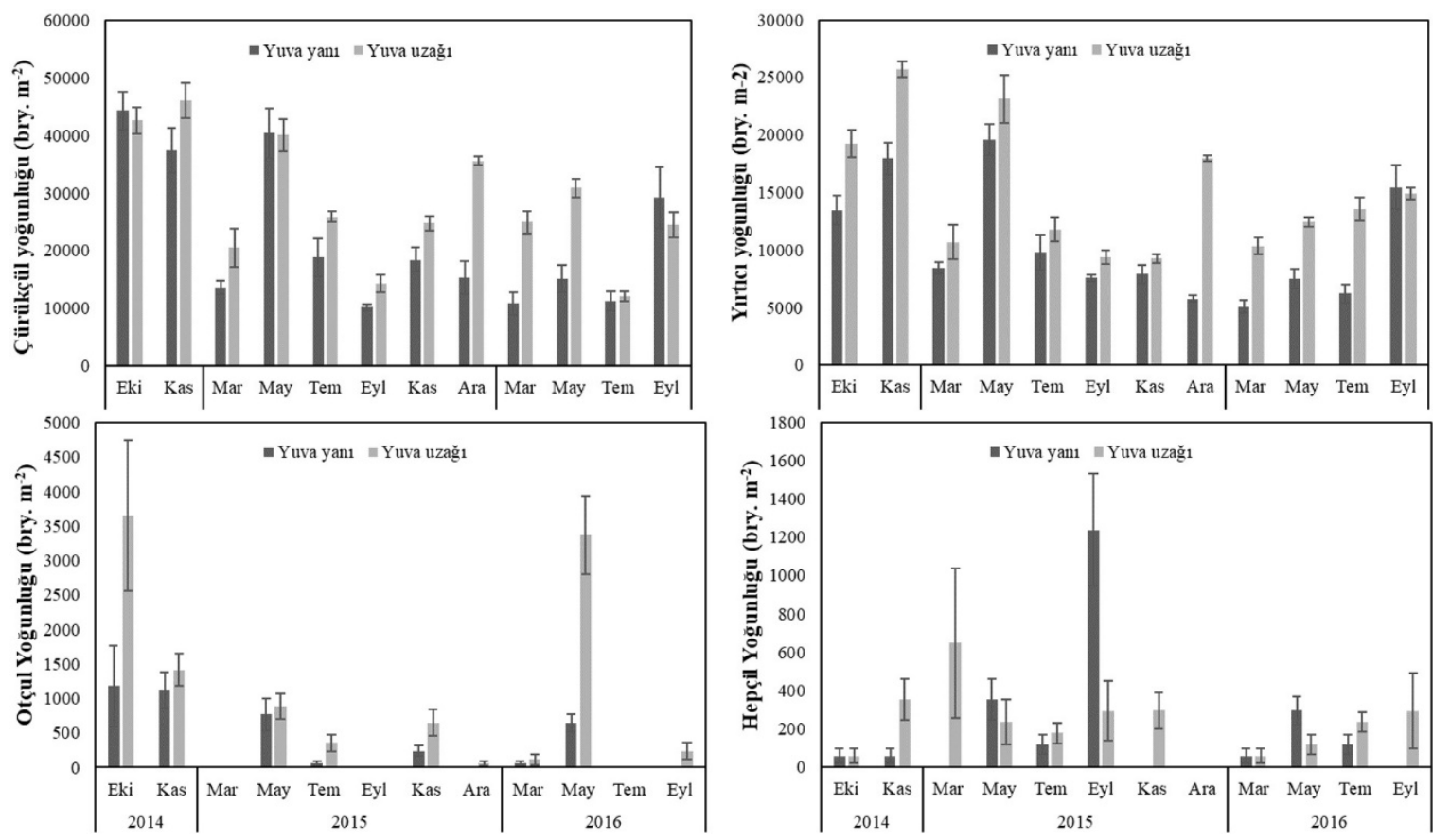

Şekil 5. Farklı beslenme alışkınlıklarına sahip mikroeklembacaklıların zamansal değişimi.

Tablo 2. Orman karıncası yuvasının yanı $(0,5 \mathrm{~m})$ ve uzağında $(10 \mathrm{~m})$ belirlenen mikroeklembacaklıların miktar ve komünite yapısına ait tekrarlı ölçümlerde varyans analiz sonuçları.

\begin{tabular}{|c|c|c|c|c|c|}
\hline & $\begin{array}{l}\text { Yuva yanı } \\
(0,5 \mathrm{~m})\end{array}$ & $\begin{array}{l}\text { Yuva uzağı } \\
(10 \mathrm{~m})\end{array}$ & $\begin{array}{l}\text { P-değeri } \\
\text { Zaman } \\
\end{array}$ & $\begin{array}{l}P \text { - değeri } \\
\text { Mesafe }\end{array}$ & $\begin{array}{l}\text { P-değeri } \\
\text { Zaman } x \text { Mesafe }\end{array}$ \\
\hline $\begin{array}{l}\text { Mikroeklembacaklı } \\
\text { yoğunluğu (bry. } \text { m}^{-2} \text { ) }\end{array}$ & $32943 \pm 2512$ & $44463 \pm 2162$ & 0,000 & 0,000 & 0,009 \\
\hline Collembola (bry. $\mathrm{m}^{-2}$ ) & $8138 \pm 774$ & $11205 \pm 884$ & 0,000 & 0,000 & 0,083 \\
\hline Acari (bry. $\mathbf{m}^{-2}$ ) & $24170 \pm 1831$ & $31999 \pm 1474$ & 0,000 & 0,000 & 0,002 \\
\hline $\mathrm{A} / \mathrm{C}$ & $4,45 \pm 0,42$ & $4,37 \pm 0,41$ & 0,000 & 0,747 & 0,009 \\
\hline Çürükçül (bry. m²) & $22032 \pm 1855$ & $28480 \pm 1472$ & 0,000 & 0,000 & 0,009 \\
\hline Yirtıcı (bry. $\mathbf{m}^{-2}$ ) & $10379 \pm 708$ & $14857 \pm 738$ & 0,000 & 0,000 & 0,001 \\
\hline Otçul (bry. m-2) & $339 \pm 95$ & $894 \pm 208$ & 0,000 & 0,001 & 0,012 \\
\hline Hepçil (bry. $\mathbf{m}^{-2}$ ) & $191 \pm 55$ & $231 \pm 61$ & 0,003 & 0,531 & 0,004 \\
\hline
\end{tabular}

\subsection{Mikroeklembacaklıların Çeşitliliği}

Karınca yuvaları, mikroeklembacaklılarının tür zenginliğini olumsuz etkilemektedir. Tür zenginliği karınca yuvasından uzaklaştıkça önemli derecede artmaktadır $(P<0,01)$. Shannon çeşitlilik indeksi yuvadan uzaklaştıkça değişmezken zaman ve mesafe bir arada değerlendirildiğinde istatistiksel farklılık göstermektedir $(P<0,05)$. Bununla birlikte Evenness inseksi karınca yuvasında uzaklaştıkça $(10 \mathrm{~m})$ önemli derecede artış göstermektedirler $(P<0,05)$.

Tablo 3. Orman karıncası yuvasının yanı $(0,5 \mathrm{~m})$ ve uzağında $(10 \mathrm{~m})$ belirlenen mikroeklembacaklıların çeşitliliğine ait bazı indislerin tekrarlı ölçümlerde varyans analiz sonuçları.

\begin{tabular}{llllll}
\hline & $\begin{array}{l}\text { Yuva yanı } \\
(\mathbf{0 , 5} \mathbf{~ m})\end{array}$ & $\begin{array}{l}\text { Yuva uzağı } \\
(\mathbf{1 0 m})\end{array}$ & $\begin{array}{l}\text { P-değeri } \\
\text { Zaman }\end{array}$ & $\begin{array}{l}\text { P-değeri } \\
\text { Mesafe }\end{array}$ & $\begin{array}{l}\text { P-değeri } \\
\text { Zaman } \boldsymbol{x} \text { Mesafe }\end{array}$ \\
\hline Tür zenginliği $(\mathbf{S})$ & $8,27 \pm 0,21$ & $8,88 \pm 0,22$ & $\mathbf{0 , 0 0 0}$ & $\mathbf{0 , 0 0 0}$ & 0,172 \\
Shannon $\left(\boldsymbol{H}^{\prime}\right)$ & $1,66 \pm 0,02$ & $1,67 \pm 0,02$ & $\mathbf{0 , 0 0 0}$ & 0,319 & $\mathbf{0 , 0 4 2}$ \\
Evenness $\left(\boldsymbol{J}^{\prime}\right)$ & $0,65 \pm 0,01$ & $0,62 \pm 0,01$ & $\mathbf{0 , 0 0 0}$ & $\mathbf{0 , 0 0 0}$ & $\mathbf{0 , 0 2 8}$ \\
\hline
\end{tabular}




\section{Tartışma}

Kırmızı orman karıncaları, nispeten büyük ve uzun süre dayanabilen kubbe biçimli yuvalar yaparlar. Genel olarak kütük üzerine yapılan yuvanın üstü ibre, dal, reçine, kabuk ve diğer otlar ile örtülerek yuva büyütülür (Bristow ve ark., 1992). Kırmızı orman karıncalarının yuva sıcaklığı erken ilkbahar ve geç sonbahar arasında genellikle hava sıcaklığından daha yüksek olmaktadır (Lenoir ve ark., 2001). Yuvalarını yaptıkları konum itibari ile güneşe bakan yuvalar yaparak yuva sıcaklığını arttırırlar. Fakat bu durum kışın kar altında da hem havadan hem de toprak sıcaklığından daha yüksek sıcaklıkta olmasını açıklamamaktadır. Bu konu hakkında farklı görüşler vardır. Yuva sıcaklığının, karıncalar ile mikrobiyal canlıların solunumu ve yuvayı oluşturan organik maddenin ayrışmasından kaynaklanan $\mathrm{CO}_{2}$ salımı nedeni ile yuvanın çevresine göre daha yüksek olduğu açıklanmaktadır (Coenen-Stass ve ark., 1980; Kadochová ve Frouz, 2014). Bu çalışmada yapılan ölçümler sonucunda da yıl boyunca yuva sıcaklığının topraktan daha sıcak olduğunu göstermektedir. Toprak nemi ve pH'sının karınca yuvasına olan mesafeden etkilenmemesi çalışma süresince farklı iki mesafeden örneklenen mikroeklembacaklıların bu çevresel faktörlerden etkilenmediğini göstermektedir. Yapılan çalışmada mikroeklembacaklıların komünite yapıları ve çeşitliliklerinde etkili olan faktörün karınca yuvası olduğunu göstermektedir.

Karınca yuvasından uzaklaştıkça mikroeklembacaklı miktarının \%34 artması, kırmızı orman karıncalarının mikroeklembacaklılar üzerinde olumsuz etkisi olduğunu açıkça göstermektedir. Akar ve Collembola taksonları toprak içerisinde miktarları en fazla olan eklembacaklılardandır (Çakır, 2019; Çakır ve Makineci, 2020). Acar ve Collembola topluluklarının yoğunlukları ile belirlenen $\mathrm{A} / \mathrm{C}$ indeksi toprak kalitesinin bir göstergesidir. Toprak kalitesinin bozulmadığ 1 doğal koşullarda akar sayısının Collembola sayısına oranı 1'den yüksektir. Toprak kalitesinin bozulması durumunda oran Collembola'ya doğru kayar ve değer düşmektedir (Menta ve ark., 2011). A/C indeksi, tarım, orman ve meraların (Menta ve ark., 2011), maden sahalarının (Menta ve ark., 2014) ve şehirleşmenin (Joimel ve ark., 2017) etkisini belirlemek için sıkça kullanılan bir indekstir. Yapılan çalışmada $\mathrm{A} / \mathrm{C}$ indeksi sonucuna göre orman karıncalarından kaynaklanan bir toprak bozulmasının olmadığı belirlenmiştir.

Mikroeklembacaklılar beslenme yapılarına göre gruplandırıldığında, hepçiller dışındaki tüm beslenme seviyesinde bulunan canlılar orman karıncalarından olumsuz etkilenmiştir. Çürükçüller en az etkilenirken en fazla otçulların etkilendiği belirlenmiştir. Orman karıncaları yuvalarını ölü örtüyü oluşturan bileşenlerden (ibre, dal vb) meydana getirdikleri için (Bristow ve ark., 1992) zaman içerisinde yuva etrafındaki ölüörtü kalınlığının azalmasına neden olmaktadırlar. Genç yuvalar etrafındaki ölüörtü kalınlığı az iken yaşlı yuvalar etrafındaki ölüörtü kalınlığ 1 daha fazla olmaktadır (Domisch ve ark., 2008). Ayrıca Cakir ve Makineci (2013) ölüörtü kalınlığı ile mikroeklembacaklı miktarının doğru orantılı olduğunu, ölüörtü kalınlığı artıkça mikroeklembacaklı miktarının arttığını belirtmiştir. Bu çalışmalar özellikle çürükçül ve otçul olan mikroeklembacaklıların miktarının karınca yuvasından uzaklaştıkça neden arttığını açıklamaktadır.

Benzer olarak, yırtıcı miktarı da yuvadan uzaklaştıkça artış göstermektedir. Orman karıncalarının besinlerini, tohum, yaprak bitleri, balözü (honeydew), larvalar ve diğer böcekler oluşturmaktadır (Skinner, 1980; Domisch ve ark., 2009; Domisch ve ark., 2016). Orman karıncaları beslenme faaliyetlerini gerçekleştirirken diğer böcekleri avladıkları için yuva etrafında bulunan farklı beslenme seviyesindeki canlıların miktarını düşürmektedir (Hawes ve ark., 2013; Parr ve ark., 2016). Ancak bu azalma sadece orman karıncalarının avlanma faaliyetleri ile değil, yırtıcılar arasındaki rekabete de bağlı olabilmektedir (Duma, 2003). Orman karıncaları yırtıcılar ile rekabet edebilmek için yırtıcılara karşı gelişmiş bir savunma sistemleri vardır ve bu nedenle yuva etrafında yırtıcı miktarı azdır (Laakso ve Setälä, 2000).

Mikroeklembacaklıların miktar ve çeşitliliğini etkileyen birçok faktör vardır. Bu faktörler arasında iklim, bitki örtüsü, ölüörtü kalitesi ve diğer canlılar sayılabilir (Wallwork, 1976). Orman ekosisteminde yaşayan mikroeklembacaklıların toprak içerisindeki dağılımları bu faktörlerin biri ya da tamamından etkilenmektedir (Ettema ve Wardle, 2002). Uygulanan farklı çeşitlilik indekslerinin hepsi hem mesafe hem de mesafe-zaman bir arada değerlendirildiğinde mikroeklembacaklı çeşitliliğinin arttığını göstermektedir.

\section{Sonuç}

Birçok ibreli ormanda bulunan ve ekosistemin önemli bir parçası olan orman karıncalarının, yuva yapma ve yiyecek arama faaliyetleri ile çevrelerine olumlu ve olumsuz etkileri olmaktadır. Literatürün aksine bu çalışmada orman karınca yuvalarının etraflarındaki toprağın pH'sını ve nem değerlerini etkilemediği belirlenmiştir. Fakat büyük yuvaları, büyük popülasyon yoğunlukları, yuvalarına karşı koruyucu olmaları ve 
yuvalarına ölüörtü taşıyarak yuva etrafındaki ölüörtü miktarını değiştirmeleri sonucunda mikroeklembacaklıların miktar ve çeşitliliğini olumsuz etkilemektedirler.

\section{Kaynaklar}

1. Bristow, C., Cappaert, D., Campbell, N., Heise, A. (1992). Nest structure and colony cycle of the Allegheny mound ant, Formica exsectoides Forel (Hymenoptera: Formicidae). Insectes Sociaux, 39: 385402.

2. Cakir, M., Makineci, E. (2013). Humus characteristics and seasonal changes of soil arthropod communities in a natural sessile oak (Quercus petraea L.) stand and adjacent Austrian pine (Pinus nigra Arnold) plantation. Environmental Monitoring and Assessment, 185: 8943-8955.

3. Coenen-Stass, D., Schaarschmidt, B., Lamprecht, I. (1980). Temperature distribution and calorimetric determination of heat production in the nest of the wood ant, Formica polyctena (Hymenoptera, Formicidae). Ecology, 61: 238-244.

4. Cole, L., Bradford, M.A., Shaw, P.J.A., Bardgett, R.D. (2006). The abundance, richness and functional role of soil meso-and macrofauna in temperate grassland-A case study. Applied Soil Ecology, 33: 186198.

5. Coleman, D. C., Callaham, M. A., Crossley, Jr. D. (2018). Fundamentals of soil ecology, 3rd Edition. Academic Press, USA.

6. Çakır, M. (2019). The negative effect of wood ants (Formica rufa) on microarthropod density and soil biological quality in a semi-arid pine forest. Pedobiologia, 77: 150593.

7. Çakır, M., Çakır, F., Yalçıntekin, H. İ. (2020). Çankırı Karatekin Üniversitesi, Orman Fakültesi Araştırma ve Uygulama Ormanında Humus Formlarının Belirlenmesi ve Değerlendirilmesi. Anadolu Orman Araștırmaları Dergisi, 6: 82-90.

8. Çakır, M., Makineci, E. (2020). Litter decomposition in pure and mixed Quercus and Fagus stands as influenced by arthropods. The Journal of Forestry Research, 31: 1123-1137.

9. Dindal, D. L. (1990). Soil biology guide. Wiley, New York.

10. Domisch, T., Finer, L., Neuvonen, S., NiemelÄ, P., Risch, A. C., Kilpeläinen, J., Ohashi, M., Jurgensen, M. F. (2009). Foraging activity and dietary spectrum of wood ants (Formica rufa group) and their role in nutrient fluxes in boreal forests. Ecological Entomology, 34: 369-377.

11. Domisch, T., Ohashi, M., Finér, L., Risch, A., Sundström, L., Kilpeläinen, J., Niemelä, P. (2008). Decomposition of organic matter and nutrient mineralisation in wood ant (Formica rufa group) mounds in boreal coniferous forests of different age. Biology and Fertility of Soils, 44: 539-545.

12. Domisch, T., Risch, A. C., Robinson, E. J. H. (2016). Wood ant foraging and mutualism with aphids. In: Jenni, A., Stockan, Elva, J.H., Robinson (Eds.), Wood Ant Ecology and Conservation. Cambridge University Press pp. 145-176.

13. Duma, I. (2003). The impact of red wood ants Formica rufa on the distribution of invertebrate fauna from the forest's floor. Annals of West University of Timisoara: Series of Biology, 1011: 121-130.

14. Ettema, C. H., Wardle, D. A. (2002). Spatial soil ecology. Trends in Ecology \& Evolution, 17: 177-183.

15. Frouz, J., Jilkova, V. (2008). The effect of ants on soil properties and processes (Hymenoptera: Formicidae). Myrmecological News, 11: 191-199.

16. Gülsoy, S., Özkan, K. (2008). Tür çeşitliliğinin ekolojik açıdan önemi ve kullanılan bazı indisler. Süleyman Demirel Üniversitesi Orman Fakültesi Dergisi, 1: 168-178.

17. Hawes, C., Evans, H. F., Stewart, A. J. (2013). Interference competition, not predation, explains the negative association between wood ants (Formica rufa) and abundance of ground beetles (Coleoptera: Carabidae). Ecological Entomology, 38: 315-322.

18. Jílková, V., Matějíček, L., Frouz, J. (2011). Changes in the pH and other soil chemical parameters in soil surrounding wood ant (Formica polyctena) nests. European Journal of Soil Biology, 47: 72-76.

19. Jílková, V., Šebek, O., Frouz, J. (2012). Mechanisms of $\mathrm{pH}$ change in wood ant (Formica polyctena) nests. Pedobiologia, 55: 247-251.

20. Joimel, S., Schwartz, C., Hedde, M., Kiyota, S., Krogh, P. H., Nahmani, J., Pérès, G., Vergnes, A., Cortet, J. (2017). Urban and industrial land uses have a higher soil biological quality than expected from physicochemical quality. Science of the Total Environment, 584: 614-621.

21. Jones, C. G., Lawton, J. H., Shachak, M. (1994). Organisms as ecosystem engineers. Oikos, 69: 373-386.

22. Jouquet, P., Dauber, J., Lagerlöf, J., Lavelle, P., Lepage, M. (2006). Soil invertebrates as ecosystem engineers: intended and accidental effects on soil and feedback loops. Applied Soil Ecology, 32: 153-164.

23. Jurgensen, M., Finer, L., Domisch, T., Kilpeläinen, J., Punttila, P., Ohashi, M., Niemelä, P., Sundström, L., Neuvonen, S., Risch, A. (2008). Organic mound-building ants: their impact on soil properties in temperate and boreal forests. Journal of Applied Entomology, 132: 266-275. 
24. Kadochová, Š., Frouz, J. (2014). Red wood ants Formica polyctena switch off active thermoregulation of the nest in autumn. Insectes sociaux, 61: 297-306.

25. Karaöz, M. Ö. (1989). Toprakların bazı kimyasal özelliklerinin (pH, karbonat, tuzluluk, organik madde, total azot, yararlanılabilir fosfor) analiz yöntemleri. Journal of the Faculty of Forestry Istanbul University, 39: $64-82$

26. Laakso, J., Salminen, J., Setälä, H. (1995). Effects of abiotic conditions and microarthropod predation on the structure and function of soil animal communities. Acta Zoologica Fennica, 196: 162-167.

27. Laakso, J., Setälä, H. (2000). Impacts of wood ants (Formica aquilonia Yarr.) on the invertebrate food web of the boreal forest floor. Annales Zoologici Fennici, 37: 93-100.

28. Lavelle, P., Bignell, D., Lepage, M., Wolters, W., Roger, P., Ineson, P., Heal, O., Dhillion, S. (1997). Soil function in a changing world: the role of invertebrate ecosystem engineers. European Journal of Soil Biology, 33: 159-193.

29. Lenoir, L. (2003). Response of the foraging behaviour of red wood ants (Formica rufa group) to exclusion from trees. Agricultural and Forest Entomology, 5: 183-189.

30. Lenoir, L., Bengtsson, J., Persson, T. (2003). Effects of Formica ants on soil fauna-results from a shortterm exclusion and a long-term natural experiment. Oecologia, 134: 423-430.

31. Lenoir, L., Persson, T., Bengtsson, J. (2001). Wood ant nests as potential hot spots for carbon and nitrogen mineralisation. Biology and Fertility of Soils, 34: 235-240.

32. Menta, C., Conti, F., Pinto, S., Leoni, A., Lozano-Fondón, C. (2014). Monitoring soil restoration in an open-pit mine in northern Italy. Applied Soil Ecology, 83: 22-29.

33. Menta, C., Leoni, A., Gardi, C., Conti, F. D. (2011). Are grasslands important habitats for soil microarthropod conservation? Biodiversity and Conservation, 20: 1073-1087.

34. Moore, J. C., Walter, D. E., Hunt, H. W. (1988). Arthropod regulation of micro and mesobiota in belowground detrital food webs. Ann. Rev. Entomol., 33: 419-439.

35. Özkan, K. (2016). Biyolojik çeşitlilik bileşenleri $(\alpha, \beta$ ve $\gamma$ ) nasıl ölçülür? SDÜ Basımevi, Isparta.

36. Özkan, K., Küçüksille, E., Ahmet, M., Gülsoy, S., Halil, S., Başar, M. (2020). Biyolojik Çeşitlilik Bileşenleri (BİÇEB) hesaplama yazılımı. Türkiye Ormancılık Dergisi, 21: 344-348.

37. Parr, C., Eggleton, P., Davies, A., Evans, T. A., Holdsworth, S. (2016). Suppression of savanna ants alters invertebrate composition and influences key ecosystem processes. Ecology, 97: 1611-1617.

38. Reznikova, Z., Dorosheva, H. (2004). Impacts of red wood ants Formica polyctena on the spatial distribution and behavioural patterns of ground beetles (Carabidae). Pedobiologia, 48: 15-21.

39. Robinson, E. J. H., Stockan, J. A., Iason, G. R. (2016). Wood ants and their interaction with other organisms. In: Stockan, J.A., Robinson, E.J.H. (Eds.), Wood ant ecology and conservation. Cambridge University Press pp. 177-206.

40. Skinner, G. (1980). The feeding habits of the wood-ant, Formica rufa (Hymenoptera: Formicidae), in limestone woodland in north-west England. The Journal of Animal Ecology: 417-433.

41. Šmilauer, P., Lepš, J. (2014). Multivariate analysis of ecological data using CANOCO. Cambridge University Press, U.K.

42. SPSS (2011). IBM SPSS statistics base 20. SPSS Incorporated, Chicago, IL.

43. Stadler, B., Schramm, A., Kalbitz, K. (2006). Ant-mediated effects on spruce litter decomposition, solution chemistry, and microbial activity. Soil Biology and Biochemistry, 38: 561-572.

44. Stockan, J. A., Robinson, E. J. (2016). Wood ant ecology and conservation. Cambridge University Press.

45. Swift, M. J., Heal, W., Anderson, J. M. (1979). Decomposition in Terrestrial Ecosystems. University of California Press, Berkeley.

46. Wagg, C., Bender, S. F., Widmer, F., van der Heijden, M. G. (2014). Soil biodiversity and soil community composition determine ecosystem multifunctionality. Proceedings of the National Academy of Sciences, 111: 5266-5270.

47. Wallwork, J. A. (1976). The Distribution and Diversity of Soil fauna. Academic Press, London. 